\title{
Prevalence and intensity of rhinoconjunctivitis in subjects with occupational asthma
}

\author{
J-L. Malo, C. Lemière, A. Desjardins, A. Cartier
}

Prevalence and intensity of rhinoconjunctivitis in subjects with occupational asthma. J-L. Malo, C. Lemière, A. Desjardins, A. Cartier. CERS Journals Ltd 1997.

ABSTRACT: Subjects with occupational asthma may also report symptoms of rhinoconjunctivitis. The aims of this study were: 1) to assess the prevalence of rhinoconjunctivitis in association with occupational asthma, and the severity of rhinoconjunctivitis according to the type of agent (high (HMW) and low (LMW) molecular weight agents) causing occupational asthma; and 2) to evaluate the timing of occurrence of symptoms of rhinoconjunctivitis in relation to those of occupational asthma.

A questionnaire on symptoms of rhinoconjunctivitis and its timing in relation to the development of chest symptoms was prospectively addressed to 143 subjects consecutively referred to an occupational asthma clinic. Objective testing through specific inhalation challenges confirmed the diagnosis of occupational asthma in 40 subjects.

Symptoms of rhinitis were reported at some time by 37 of the 40 subjects $(92 \%)$, and of conjunctivitis by 29 of the $\mathbf{4 0}$ subjects $(\mathbf{7 2 \%})$. The prevalence of symptoms was not different for HMW and LMW agents, although rhinitis was more intense for HMW (19 out of 24 subjects with three or more of the following symptoms: runny nose, itchy nose, nasal blockage, and sneezing) than for LMW (5 out of 14 subjects) $(\mathbf{p}<0.01)$. There were significantly fewer subjects with occupational asthma due to LMW agents, with rhinitis appearing before asthma $(p=0.03)$. Figures for conjunctivitis showed a similar trend, but did not reach statistical significance.

In conclusion, symptoms of rhinoconjunctivitis are often associated with occupational asthma. Rhinitis is less pronounced in the case of low molecular weight agents, but more often appears before occupational asthma in the case of high molecular weight agents.

Eur Respir J 1997; 10: 1513-1515.
Dept of Chest Medicine, Hôpital du SacréCoeur, Montreal, Canada.

Correspondence: J-L. Malo

Dept of Chest Medicine

Hôpital du Sacré-Coeur

5400 West Gouin

Montreal

Canada H4J 1C5

\section{Keywords: Asthma}

occupational asthma

rhinitis

Received: November 211996

Accepted after revision March 261997

JLM is a research scholar with the Fonds de la Recherche en Santé du Québec and the Université de Montréal School of Medicine. CL is the recipient of a research grant from L'Association recherche et partage (Paris, France). This study was partly funded by the Centre Québécois d'Excellence en Santé Respiratoire.
Symptoms of rhinoconjunctivitis may accompany occupational asthma [1], as described many years ago by Ramazzini in the case of grain-handlers, and more recently reviewed [2]. However, to our knowledge, the prevalence and intensity of symptoms of rhinoconjunctivitis in subjects with occupational asthma have not been prospectively explored. Moreover, it is unknown whether symptoms of rhinoconjunctivitis develop before or at the same time as the onset of asthma symptoms. Finally, the frequency and time of onset of rhinoconjunctivitis in relation to occupational asthma need to be distinguished for high molecular weight (HMW) and low molecular weight (LMW) agents.

We hypothesized that rhinoconjunctivitis would be more frequent, more severe, and would precede the onset of asthma in subjects exposed to HMW agents, by comparison with those exposed to LMW agents. Nasal and ocular symptoms that precede or coexist with asthma symptoms are a feature of immunoglobulin E (IgE)mediated conditions, generally linked to HMW agents, such as animal-derived proteins, house dust mites or pollens. By comparison, symptoms of rhinoconjunctivitis would generally accompany, but not precede, the onset of occupational asthma due to LMW agents. To verify this, subjects consecutively referred to a tertiary clinic for possible occupational asthma were assessed, by means of a questionnaire on ocular and nasal symptoms. Objective testing through specific inhalation challenges was then performed, and 40 subjects with occupational asthma were identified.

\section{Materials and methods}

\section{Subjects}

All subjects $(n=143)$ referred to a tertiary care occupational asthma clinic during the period from December 1993 to December 1995 were initially asked to complete the study questionnaire. Of these, a group of 45 subjects were excluded from the analysis, on the grounds that: the investigation excluded asthma at the time of a working period (normal bronchial responsiveness to inhaled methacholine); they were cases of reactive airways dysfunction syndrome; their lung function tests were too low to allow for objective testing; or they abandoned further testing. Of the remaining 98 subjects, $42(43 \%)$ were referred by the Workers' Compensation Board and $56(57 \%)$ by their treating physician. Of these, 
a group of 58 subjects was assessed, with a combination of specific inhalation challenges and/ or peak expiratory flow monitoring, and the diagnosis of occupational asthma was discarded (23 subjects with personal or nonoccupational asthma, 16 with hyperventilation, and 19 with other conditions).

Ultimately, the diagnosis of occupational asthma was objectively confirmed in a group of 40 subjects with specific inhalation challenges, using a methodology described previously [3]. This group of 40 subjects comprised 26 males and 14 females, with a mean age of 37 yrs (range 22-61 yrs). Their mean duration of exposure to the presumed asthmagen was 10 yrs (range 0.5-35 yrs), and they had been symptomatic for 5 yrs (range $0.2-30 \mathrm{yrs})$. The mean baseline forced expiratory volume in one second (FEV1) was $87 \%$ of predicted value (range $52-123 \%$ pred) [4], and the FEV1/forced vital capacity (FVC) ratio was $89 \%$ pred (range $47-105 \%$ pred). The causal agent was of HMW in 24 instances (flour 13 , latex 5 , coffee 2 , and one each of spices, hens, grain and cacao), and of LMW in 14 instances (isocyanates 3 , persulphate 3 , formaldehyde 3 , Western red cedar 2 , methacrylate 2 , and polyethylene 1 ). In the two remaining subjects, the occupational asthma was due to ash wood dust and cotton dust, for which the molecular weight of the agent could not be determined.

\section{Methods}

The closed questionnaire was administered by three physicians (JLM, AC and AD) at the time of the initial visit, i.e. before investigation. It collected information on the nature of nasal symptoms (sneezing, runny nose, itchy nose, nasal blockage) and ocular symptoms (watery, red, itchy eyes), and their temporal relationship with the onset of respiratory symptoms (before, at the same time, after).

\section{Analysis of results}

Comparison of the presence (at least one symptom) or absence of rhinitis and conjunctivitis was made for subjects with occupational asthma and in those in whom the diagnosis was excluded. The nature and intensity of symptoms (number of nasal or ocular symptoms) and their timing in relation to the onset of asthma symptoms were obtained. Comparison of results was made for HMW and LMW agents. Chi-squared analysis or Fisher exact probability test (when the number was less than five in one cell) was used for statistical comparison, with a p-value equal to or less than 0.05 being considered significant.

\section{Results}

The majority of subjects with occupational asthma (37 out of $40,92 \%$ ) reported rhinitis symptoms. Symptoms of conjunctivitis were slightly less common (29 out of $40,72 \%$ ). Symptoms of rhinitis were less common in the group of 58 subjects in whom the diagnosis of occupational asthma was discarded (39 out of $58,67 \%$ ) $(p<0.01)$. They were also less common in the subgroup of subjects with personal or nonoccupational asthma (17 out of $23,74 \%)(p=0.04)$ The same applied for symptoms of conjunctivitis $(25$ out of $58,43 \%(p<0.01)$ in the whole negative group; and 18 out of $23,78 \%(\mathrm{p}<$ 0.01 ), in the subgroup of subjects with personal asthma).
Table 1 presents information on the nature, intensity and timing of nasal and ocular symptoms in the 40 subjects with a confirmed diagnosis of occupational asthma. Sneezing was the most frequent nasal symptom in the case of HMW agents, as compared to a runny nose for LMW agents. Sneezing was more common for HMW than for LMW agents. Itchy eyes were the predominant ocular symptom for HMW and LMW agents. The intensity of nasal symptoms was significantly more pronounced in the case of HMW agents, with a trend for similar findings in the case of ocular symptoms. In the total group of 98 subjects, including the 40 in whom the diagnosis of occupational asthma was confirmed, there were no significant differences in the prevalence of rhinoconjunctivitis in those referred by the Workers' Compensation Board (83\%) and in subjects referred by their treating physicians $(77 \%)$.

Table 1. - Nature, intensity and timing of symptoms according to the nature of the agent

\begin{tabular}{|c|c|c|c|}
\hline & $\begin{array}{l}\text { HMW } \\
(n=24)\end{array}$ & $\begin{array}{l}\text { LMW } \\
(\mathrm{n}=14)\end{array}$ & $\mathrm{p}$-value \\
\hline \multicolumn{4}{|l|}{ Nature of symptoms } \\
\hline \multicolumn{4}{|l|}{ Nasal } \\
\hline Sneezing & 24 & 6 & $<0.0001$ \\
\hline Runny nose & 20 & 9 & 0.2 \\
\hline Blocked nose & 17 & 7 & 0.2 \\
\hline Itchy nose & 17 & 7 & 0.2 \\
\hline \multicolumn{4}{|l|}{ Ocular } \\
\hline Itchy eyes & 19 & 8 & 0.15 \\
\hline Runny eyes & 13 & 4 & 0.13 \\
\hline Red eyes & 13 & 5 & 0.2 \\
\hline \multicolumn{4}{|c|}{ Intensity (number) of symptoms } \\
\hline \multicolumn{4}{|c|}{ Nasal } \\
\hline None & 0 & 2 & \\
\hline One & 2 & 2 & \\
\hline Two & 3 & 5 & \\
\hline Three & 6 & 2 & $0.02 \ddagger$ \\
\hline Four & 13 & 3 & $0.05^{\$}$ \\
\hline \multicolumn{4}{|l|}{ Ocular } \\
\hline None & 5 & 5 & \\
\hline One & 5 & 4 & \\
\hline Two & 4 & 2 & $0.2 \ddagger$ \\
\hline Three & 10 & 3 & $0.2^{\$}$ \\
\hline \multirow{2}{*}{\multicolumn{4}{|c|}{$\begin{array}{l}\text { Timing of symptoms in relation to the onset of asthma } \\
\text { Nasal }\end{array}$}} \\
\hline & & & \\
\hline Before & 14 & 3 & $0.03^{\#}$ \\
\hline At the same time & 9 & 9 & \\
\hline After & 1 & 0 & \\
\hline \multicolumn{4}{|l|}{ Ocular } \\
\hline Before & 12 & 3 & $0.08^{\#}$ \\
\hline At the same time & 5 & 6 & \\
\hline After & 2 & 0 & \\
\hline
\end{tabular}

The data exclude two subjects who were exposed to agents that could not be classified as HMW or LMW (cotton dust and ash wood dust). $¥$ : comparing the number of subjects with $\geq 3$ symptoms in the case of nasal symptoms and $\geq 2$ symptoms in the case of ocular symptoms; $\$$ : comparing the number of subjects with 4 symptoms in the case of nasal symptoms and 3 symptoms in the case of ocular symptoms; \#: comparing the number of subjects with symptoms appearing before as opposed to at the same time or after lower respiratory symptoms. Chi-squared analysis or Fisher exact probability test in the case of less than five in any one cell. HMW: high molecular weight; LMW: low molecular weight. 
Symptoms of rhinitis appeared before the onset of asthma in 14 out of 24 instances for HMW, while this was the case in only 3 out of 14 subjects in the case of LMW agents (table 1). Similarly, symptoms of conjunctivitis appeared before the onset of asthma in 12 out of 24 subjects exposed to HMW agents (although this was not significant), whereas this was the case in only 3 out of 14 subjects for LMW agents. In only one and two subjects, nasal and ocular symptoms, respectively, followed the onset of asthma. In those subjects for whom symptoms of rhinoconjunctivitis appeared before the onset of asthma, the mean interval was 22 months, and the range was wide ( 1 month to $8 \mathrm{yrs}$ ).

\section{Discussion}

Rhinitis and conjunctivitis, either isolated or in combination, often accompany asthma [5]. Although the same applies for occupational asthma [6], the prevalence of symptoms of rhinoconjunctivitis at the time of the diagnosis of occupational asthma has not to our knowledge been consecutively assessed in subjects referred to a clinic. Symptoms of rhinoconjunctivitis were present in all but two of the present sample of 40 subjects with occupational asthma. They were as frequent in the case of LMW and HMW agents. In several crosssectional surveys in high-risk workforces, we found that rhinoconjunctivitis was more frequent than occupational asthma in the case of HMW agents. It was reported by $32 \%$ of 193 subjects exposed to psyllium [7], and by $36 \%$ of 162 subjects exposed to guar gum [8]. Moreover, in these surveys, rhinoconjunctivitis was present in all cases of occupational asthma. Rhinoconjunctivitis affected 35 out of $46(76 \%)$ subjects with occupational asthma due to snow-crab [9]. It seemed as common in the case of a LMW agent, spiramycin, where it was observed in 15 out of $48(31 \%)$ exposed subjects. As for the HMW agents reported above, the three subjects with occupational asthma to spiramycin also reported symptoms of rhinoconjunctivitis [10]. It is possible that the high prevalence of rhinoconjunctivitis symptoms could be attributed to other factors, in addition to work exposure. Indeed, 33 of the 40 subjects with occupational asthma were atopic. Although the questionnaire addressed nasal and ocular symptomology in relation to the development of lower respiratory symptoms, it is possible that sensitization to common allergens could have been responsible for the symptoms.

Although symptoms of rhinoconjunctivitis were as prevalent in the cases of HMW and LMW agents, they were more marked, as assessed by the variety of symptoms encountered, with HMW cases. Besides the molecular weight of the agent and the IgE-mediated mechanism generally involved in the case of HMW agents, one possible explanation for this might be the physical nature of the agent. HMW agents generally exist as dry or liquid aerosol, whereas LMW agents are more generally vapours. Aerosols may more readily deposit in the upper airways and cause symptoms. Finally, it is possible that subjects with nasal obstruction are more prone to mouth breathing, implying an increased risk for inhaling agents directly into the lower airways without passing the nasal filter.

According to the history obtained at the time of diagnosis of occupational asthma, symptoms of rhinitis gen- erally appeared at the same time as symptoms of asthma in the case of LMW agents, whereas it either preceded or accompanied symptoms of asthma for HMW agents. Recall biases cannot be excluded, because subjects were questioned at the time they were referred and not at the time of onset of symptoms, which had started several years before in some subjects. CHAN-YEUNG and DESJARDINS [11] prospectively identified four subjects with normal bronchial responsiveness who developed occupational asthma at a later stage. Two of these subjects had symptoms of rhinitis at the time of the first assessment.

We feel that the information on symptoms of rhinoconjunctivitis might be useful in the investigation of occupational asthma. In the case of high molecular weight agents, the appearance of rhinoconjunctivitis in a sensitized subject might be a marker of the likelihood of developing occupational asthma. However, the predictive value of having such a symptomatology and having developed immunoglobulin E-dependent sensitization on the development of occupational asthma remains to be assessed for high molecular weight agents.

Acknowledgement: The authors would like to thank L. Schubert for reviewing this manuscript.

\section{References}

1. Bernstein DI. Clinical assessment and management of occupational asthma. In: Bernstein IL, Chan-Yeung M, Malo JL, Bernstein DI, eds. Asthma in the workplace. New York, Marcel Dekker Inc., 1993; pp. 103-123.

2. Rosenberg N, Gervais P. Rhinites allergiques professionnelles. Arch Mal Prof 1986; 47: 21-25.

3. Cartier A, Malo JL. Occupational challenge tests. In: Bernstein IL, Chan-Yeung M, Malo JL, Bernstein DI, eds. Asthma in the Workplace. New York, Marcel Dekker Inc., 1993; pp. 215-247.

4. Knudson RJ, Lebowitz MD, Holberg CJ, Burrows B. Changes in the normal maximal expiratory flow-volume curve with growth and aging. Am Rev Respir Dis 1983; 127: 725-734.

5. Busse WW, Holgate ST. Asthma and rhinitis. Oxford, Blackwell Scientific Publications, 1995.

6. Sternberg L, Sorrell AH. Occupational asthma and vasomotor rhinitis: an outline of some common industries where these symptoms are initiated. NY State J Med 1941; 41: 1649-1652.

7. Malo JL, Cartier A, L'Archevêque J, et al. Prevalence of occupational asthma and immunologic sensitization to psyllium among health personnel in chronic care hospitals. Am Rev Respir Dis 1990; 142: 1359-1366.

8. Malo JL, Cartier A, L'Archevêque J, et al. Prevalence of occupational asthma and immunologic sensitization to guar gum among employees at a carpet-manufacturing plant. J Allergy Clin Immunol 1990; 86: 562-569.

9. Cartier A, Malo JL, Forest F, et al. Occupational asthma in snow crab-processing workers. J Allergy Clin Immunol 1984; 74: 261-269.

10. Malo JL, Cartier A. Occupational asthma in workers of a pharmaceutical company processing spiramycin. Thorax 1988; 43: 371-377.

11. Chan-Yeung M, Desjardins A. Bronchial hyperresponsiveness and level of exposure in occupational asthma due to Western red cedar (Thuja plicata): serial observations before and after development of symptoms. Am Rev Respir Dis 1992; 146:1606-1609. 